\title{
BIOCOMBUSTIVEIS NA BUSCA DE ALTERNATIVAS PARA A AGRICULTURA FAMILIAR: AÇÕES E EXPECTATIVAS DA COOPERBIO NO NOROESTE RIOGRANDENSE
}

\author{
Hoyêdo Nunes Lins' \\ Rinald Boassi
}

\begin{abstract}
Resumo
A produção de biocombustíveis pode abrir novas possibilidades para a agricultura familiar no Brasil. O artigo explora essa questão em estudo sobre a Cooperativa Mista de Produção, Industrialização e Comercialização de Biocombustíveis do Brasil Ltda. (COOPERBIO), criada em 2005 movimentos sociais rurais no noroeste do Rio Grande do Sul. Após caracterizar a produção de biocombustíveis e descrever a região implicada, o texto apresenta as ações para obter álcool e óleo combustível pela organização de grupos familiares, com produção consorciada de alimentos e combustíveis sob princípios agroecológicos. Depois são discutidas as perspectivas para a agricultura familiar e o desenvolvimento local.
\end{abstract}

Palavras-chave: Biocombustíveis, COOPERBIO, agricultura familiar Classificação JEL: Q13, Q42

\section{INTRUDUÇÃO}

A agricultura familiar padece de grandes dificuldades no Brasil, apesar da sua importância na produção de alimentos. A recente investida nacional em

Professor do Departamento de Ciências Econômicas e do Programa de Pós-Graduação em Economia da UFSC. Graduado em Ciências Econômicas e Mestrando em Economia na UFSC. 
biocombustíveis, estimulada pelas atuais condições de produção e oferta de combustíveis fósseis e suas implicações (A brighter..., 2001), estaria a acenar positivamente para esse segmento do mundo rural. Tal aceno exibe amparo institucional, como ilustrado pelo Programa Nacional de Produção e Uso de Biodiesel (PNPB), em particular o Selo Combustível Social, atribuído aos produtores de biodiesel que adquirem matéria-prima desses agricultores.

Embora a aposta nos biocombustíveis pareça promissora para a agricultura familiar, na percepção dos movimentos sociais rurais, benefícios efetivos só virão por medidas de suas próprias organizações, em nível local. Essa questão é o objeto deste artigo, que aborda uma experiência de organização cooperativa que pretende envolver famílias de agricultores na economia dos biocombustíveis: a Cooperativa Mista de Produção, Industrialização e Comercialização de Biocombustíveis do Brasil Ltda. (COOPERBIO), criada em 2005 por pequenos agricultores ligados ao Movimento dos Pequenos Agricultores (MPA).

Inicialmente caracteriza-se a produção de biocombustíveis, destacando o espaço da pequena agricultora. Em seguida, após descrever a área de atuação da COOPERBIO, apresentam-se, com base em pesquisa direta, as iniciativas realizadas pela cooperativa até o período da pesquisa. Posteriormente discutem-se o sentido e as possibilidades da iniciativa, considerando as problemáticas da agricultura familiar e do desenvolvimento em nível local.

\section{PRODUÇÃO DE BIOCOMBUSTÍVEIS: O ESPAÇO DAAGRI- CULTURA FAMILIAR}

O Brasil se destaca pela alta presença de fontes renováveis na sua oferta interna de energia. Em 2004, essas fontes não superavam 13,2\% e 6,1\% da oferta de energia no mundo e nos países da Organização para a Cooperação e Desenvolvimento Econômico, respectivamente, mas no Brasil alcançavam 44,5\% em 2005 (Brasil, 2007). Essa presença exibe uma composição equilibrada de três modos de geração: energia hidráulica e eletricidade (14,8\%), lenha e carvão vegetal (13\%) e produtos da cana-de-açúcar $(13,8 \%)$, a terceira com rápida expansão recente.

É neste quadro que se insere o atual esforço do país para produzir biocombustíveis (sobretudo o biodiesel e o álcool combustível, ou etanol): um 
Biocombustíveis na busca de alternativas para a agricultura familiar: ações e expectativas da COOPERBIO no noroeste riograndense

uso de fontes renováveis já comparativamente alto, mas com grande margem para ampliação. Isso é merecedor de realce em face das ameaças ambientais incrustadas no modelo energético prevalecente no planeta. Mas também por questões socioeconômicas se justifica a ênfase nos biocombustíveis, pois suas cadeias produtivas permitem envolver contingentes rurais com acenos positivos em termos de trabalho e renda. É difícil recusar o apelo que isso representa, sobretudo perante as dificuldades da pequena agricultura.

Como se apresentam as cadeias produtivas do biodiesel e do álcool, e qual o espaço possível para os pequenos agricultores?

AAgência Nacional de Petróleo, Gás Natural e Biocombustíveis (ANP) caracteriza o biodiesel como "combustível para motores a combustão interna com ignição por compressão, renovável e biodegradável, derivado de óleos vegetais ou de gorduras animais, que possa substituir parcial ou totalmente o óleo diesel de origem fóssill" (Medida..., 2004). Sua participação em misturas com o último, prevista na Resolução no 42, de 24/11/2004, do Ministério de Minas e Energia (Resolução..., 2004), é indicada pela notação Bx (por exemplo, B100 significaria biodiesel puro). Já o álcool apresenta-se como álcool hidratado, de uso direto, e como álcool anidro, incorporado como aditivo à gasolina. A diferença refere-se à concentração, mostrada pelo grau GL (Gay-Lussac): é hidratado o álcool com 96 GL (quer dizer, 96\% de álcool e 4\% de água); é anidro o álcool com 99,5 GL.

Os óleos que dão origem ao biodiesel podem ter origem vegetal, animal ou residual. Os primeiros provêm de diferentes fontes oleaginosas; os segundos associam-se, por exemplo, à gordura de suínos e bovinos e ao óleo de peixe; e os terceiros são obtidos de diferentes resíduos humanos e industriais. A maior possibilidade de participação da agricultura familiar reside na produção de matéria-prima vegetal, cabendo assinalar que as culturas fornecedoras de óleos e gorduras são perenes e temporárias, com rendimento diferenciado conforme o tipo de oleaginosa e a região de cultivo.

No Brasil, a matéria-prima básica para o álcool é a cana-de-açúcar, embora vegetais como beterraba, milho e mandioca também possam ter uso. A cana-de-açúcar permite vantagens ao país perante outras nações produtoras (Andreoli; Souza, 2006). Isso é verdadeiro, por exemplo, quando se compara o rendimento da cana-de-açúcar ao do milho, matéria-prima dominante nos Estados Unidos, segundo maior produtor de álcool combustível. 
Mas não é só produzindo matéria-prima que a agricultura familiar tem espaço. Sob certas condições, também no processo de produção do combustível existem possibilidades.

A produção de biodiesel implica converter o óleo vegetal pela separação da glicerina. Um processo para tanto é a transesterificação, uma reação de óleos e gorduras (triglicerídeos) com álcoois (metanol ou etanol) envolvendo um catalisador. O outro é craqueamento catalítico ou térmico, em que há quebra de moléculas pelo intenso aquecimento. No Brasil, a transesterificação é o processo mais utilizado devido ao menor custo permitido pelo emprego de etanol. Quanto ao álcool, sua produção a partir da cana-deaçúcar envolve fermentar o caldo, obtido via moagem, e destilar. Ao lado do produto final, esse processo gera co-produtos na forma de torta, bagaço e vinhoto, utilizáveis na propriedade agrícola.

O envolvimento de pequenos agricultores na obtenção de biocombustíveis depende dos "modelos de produção" utilizados. Sobre o biodiesel, vale observar que a produção de óleo combustível é parte do processo gerador do primeiro. São dois os modelos de produção desse combustível. Um tem pequena escala, destinando-se à "produção independente de combustível, de forma auto-sustentável, para uso em máquinas agrícolas ou em motores diesel para a geração de energia”. (UnB, s/d). Sem envolver transesterificação, e sim craqueamento por micro-usinas de bio-óleo, tal modelo autoriza pulverização de pequenos estabelecimentos, com comercialização local. O outro modelo tem escala industrial, podendo atingir capacidade (com transesterificação) de 60 mil litros diários, equivalentes a 20 milhões de litros anuais. Pelos custos, sequer os mini-sistemas (sem falar do modelo industrial) podem ser implantados em pequenas propriedades individuais, sendo necessário o envolvimento cooperativo e numeroso de agricultores. Em regra, a participação dos pequenos agricultores vai só até a obtenção do óleo vegetal bruto, que é depois transportado para uma usina central de refino.

Também na produção de álcool coexistem modelos de distintas escalas, de grandes usinas a microdestilarias. A grande escala, com elevadas necessidades de área e investimento, é a base do abastecimento nacional. Estimativa feita no âmbito do BNDES (Ampliação..., 2003) indica que uma usina para 450 mil litros diários de álcool anidro exigiria, com rendimento de 80 litros por tonelada de cana e produtividade média de 76 toneladas de 
Biocombustíveis na busca de alternativas para a agricultura familiar: ações e expectativas da COOPERBIO no noroeste riograndense

cana por hectare, cerca de 13 mil hectares de área de corte anualmente. A operação de uma tal usina requereria um investimento industrial de $\mathrm{R} \$ 80$ a $\mathrm{R}$ \$ 110 milhões e investimentos agrícolas na faixa de R $\$ 40$ milhões. Assim, o modelo de produção de álcool capaz de envolver pequenos agricultores restringe-se às microdestilarias.

\section{O CONTEXTO REGIONAL DA COOPERBIO: ALGUNAS NOTASO}

A Cooperativa Mista de Produção, Industrialização e Comercialização de Biocombustíveis do Brasil Ltda. (COOPERBIO) atua em área que abrange 61 municípios da mesorregião noroeste do Rio Grande do Sul e com cerca de 467 mil habitantes no Censo de 2000, quase metade vivendo na zona rural. Quase todos os municípios se distribuem nas microrregiões de Frederico Westphalen (26 municípios), Três Passos (15) e Carazinho (13), pertencendo os restantes às microrregiões de Ijui (4), Passo Fundo (2) e Erechim (1).

$\mathrm{Na}$ divisão do estado em Conselhos Regionais de Desenvolvimento Econômico e Social (COREDE), quase todos os municípios estão no COREDE Médio Alto Uruguai (sendo Frederico Westphalen o município mais populoso), no COREDE Produção (destacando-se Passo Fundo, seguido de Carazinho) e no COREDE Noroeste Colonial (sobressaindo Ijui e depois Panambi). Esses Conselhos formam área heterogênea em termos socioeconômicos. Enquanto no COREDE Produção o setor industrial tem forte presença na estrutura do Valor Adicionado Bruto (VAB), no COREDE Médio Alto Uruguai é a agricultura que marca presença. E a participação nos totais gaúchos de Produto Interno Bruto (PIB) e população é bem distinta: o COREDE Produção representa não muito menos que o dobro do COREDE Noroeste Colonial e o triplo ou mais do COREDE Médio Alto Uruguai (Tabela 1).

Essa área integra a grande região norte do estado gaúcho na regionalização tripartite usada por Bandeira (2003), um território com "predomínio da pequena e média propriedade; região heterogênea, onde uma produção inicialmente muito diversificada cedeu espaço, nas últimas décadas, em muitas áreas, para as lavouras mecanizadas do trigo e da soja.” (p. 521). 
A soja, em particular, penetrou fortemente, primeiro próximo ao Rio Uruguai, depois ao sul (sobressaindo Carazinho e Passo Fundo), ao ritmo dos impulsos ligados aos preços internacionais, ao aumento do mercado e aos incentivos governamentais às exportações.

Tabela 1 - População, PIB e Valor Adicionado Bruto (VAB) nos COREDES que concentram os municípios da COOPERBIO - 2004

\begin{tabular}{|c|c|c|c|c|c|c|c|c|}
\hline \multirow[b]{2}{*}{ COREDES } & \multirow{2}{*}{$\begin{array}{l}\mathrm{N}^{\circ} \\
\text { muni- } \\
\text { cípios }\end{array}$} & \multicolumn{2}{|c|}{ População } & \multicolumn{2}{|l|}{ PIB } & \multicolumn{3}{|c|}{ Estrutura do VAB (\%) } \\
\hline & & $\begin{array}{c}\text { Mil } \\
\text { Habit. }\end{array}$ & $\%$ & $\begin{array}{c}\mathrm{R} \$ \\
\text { Bilhões }\end{array}$ & $\%$ & $\begin{array}{c}\text { Agri- } \\
\text { cultura }\end{array}$ & $\begin{array}{c}\text { Indús- } \\
\text { tria }\end{array}$ & $\begin{array}{l}\text { Ser- } \\
\text { viços }\end{array}$ \\
\hline Produ & 34 & 443,4 & 4,1 & 6,0 & 4,2 & 27,0 & 31,3 & 41,7 \\
\hline Noroeste Colonial & 32 & 306,1 & 2,8 & 3,5 & 2,4 & 34,1 & 23,2 & 42,7 \\
\hline Médio Alto Uruguai & 30 & 176,4 & 1,6 & 1,6 & 1,1 & 52,5 & 10,8 & 36,7 \\
\hline Rio Grande do Sul & 467 & $10.726,1$ & 100 & 142,9 & 100 & 16,3 & 42,7 & 41,0 \\
\hline
\end{tabular}

Fonte: Fundação de Economia e Estatística/Núcleo de Contabilidade Social. Obtido em: <www. fee.tche.br/sitefee/pt/content/estatisticas/pg_pib_municipal_destaques_texto.php $>$ Acesso em: ago. 2007

O dinamismo da soja foi intenso em nível estadual nos anos 70 (Alves, 2006), depois arrefecendo devido ao término do financiamento de baixo custo e à crise do cooperativismo no Rio Grande do Sul (Bandeira, 1995). Mas até recentemente esse cultivo chama a atenção: Lazzari (2005) sublinha que, no início da atual década, as microrregiões de Passo Fundo, Ijui e Carazinho figuravam entre as de crescimento da área plantada de soja, com franco recuo de outras culturas, notadamente o milho. Historicamente, a conseqüência do turbilhão sojicultor foi uma grande mudança no meio rural gaúcho, em termos produtivos e sociais, com tradução no surgimento do que Schneider (1995) chamou de "agricultores profissionais", integrados ao padrão agroindustrial tornado prevalecente. Esse processo foi acompanhado no noroeste gaúcho por notável expansão do setor de máquinas e implementos agrícolas, sendo principalmente envolvidos municípios como Panambi e Passo Fundo (Castilhos, 2007).

Mas o processo de modernização não incorporou todos os agricultores. Para Mertz (2004) muitos ficaram de fora, a sua marginalizaçãoexclusão figurando entre as causas dos altos níveis de pobreza da área. 
Biocombustíveis na busca de alternativas para a agricultura familiar: ações e expectativas da COOPERBIO no noroeste riograndense

Dados do Atlas do Desenvolvimento Humano no Brasil (Atlas..., 2003) mostram que, em 2000, não havia um só município no espaço da COOPERBIO com renda per capita ao menos próxima da renda per capita média do estado. Alguns municípios tinham números muito baixos, destacando-se Redentora, na Microrregião de Três Passos, e Cristal do Sul, na Microrregião de Frederico Westphalen, com distantes da média estadual em $73 \%$ e $69 \%$, pela ordem. O quadro de dificuldades permanece quando se considera o Índice de Desenvolvimento Humano Municipal (IDHM), também presente no Atlas: apenas 5 municípios apresentavam IDHM superior à média estadual (Quadro 1).

Essa situação espelha os problemas do noroeste riograndense nos anos 80 e 90. É reflexo de uma política econômica que cortou de subsídios, diminuiu o financiamento, alterou medidas voltadas à comercialização e aumentou os juros, e também da deterioração da conjuntura internacional, principalmente quanto ao encolhimento dos preços de produtos chaves da região, como a soja. Ora, o "desempenho da agropecuária regional nesse período propaga-se para os demais setores, resultando em uma queda na economia da região no contexto estadual.” (Caracterização..., 2000, p. 148). Assim, igualmente pelas pressões por reestruturação ligadas ao aumento da concorrência, subseqüente à abertura comercial do país na década de 90, o emprego industrial se modificou, com queda vertiginosa no segmento de máquinas e implementos agrícolas.

Daí não surpreender uma dinâmica populacional com clara tendência ao abandono da área. Apenas 15\% dos municípios abrangidos pela COOPERBIO não registraram perda absoluta de população entre os censos de 1991 e 2000, segundo o Atlas (2003). Crescimento populacional algo expressivo ocorreu só em poucos municípios mais populosos, destacandose os aumentos registrados em Sarandi (18\%), Panambi (11\%) e Frederico Westphalen (7,3\%). De todo modo, o padrão de centralidade urbana em nível de mesorregião manteve-se inalterado, sendo até fortalecido: as aglomerações descontínuas formadas por Ijui, Cruz Alta, Santa Rosa, Santo Ângelo, Horizontina e Panambi, num caso, e por Passo Fundo, Carazinho, Erechim e Maraú, no outro, a primeira representando um eixo industrial e a segunda, um importante eixo agroindustrial, permanecem vertebrando a estrutura espacial da região (Caracterização..., op cit.). 


\begin{tabular}{|c|c|c|c|c|c|}
\hline $\begin{array}{l}\text { Micror- } \\
\text { Região }\end{array}$ & Município & IDHM & $\begin{array}{l}\text { Micror- } \\
\text { Região }\end{array}$ & Município & IDHM \\
\hline $\begin{array}{l}\text { Cara- } \\
\text { zinho }\end{array}$ & $\begin{array}{l}\text { Barra Funda } \\
\text { Boa Vista das Missões } \\
\text { Cerro Grande } \\
\text { Chapada } \\
\text { Jaboticaba } \\
\text { Lajeado do Bugre } \\
\text { Nova Boa Vista } \\
\text { Novo Barreiro } \\
\text { Palmeira das Missões } \\
\text { Sagrada Família } \\
\text { Sarandi } \\
\text { São José das Missões } \\
\text { S. Pedro das Missões } \\
\end{array}$ & $\begin{array}{l}0,813 \\
0,767 \\
0,725 \\
0,816 \\
0,734 \\
0,711 \\
0,815 \\
0,767 \\
0,784 \\
0,735 \\
0,791 \\
0,753 \\
0,784^{\star}\end{array}$ & \multirow{4}{*}{$\begin{array}{l}\text { Frede- } \\
\text { rico } \\
\text { West- } \\
\text { phalen }\end{array}$} & \multirow{4}{*}{$\begin{array}{l}\text { Alpestre } \\
\text { Ametista do Sul } \\
\text { Caiçara } \\
\text { Constantina } \\
\text { Cristal do Sul } \\
\text { Dois Irmãos das } \\
\text { Missões } \\
\text { Engenho Velho } \\
\text { Erval Seco } \\
\text { Frederico Westphalen } \\
\text { Gramado dos Loureiros } \\
\text { Irai } \\
\text { Liberato Salzano } \\
\text { Nonoai } \\
\text { Novo Tiradentes } \\
\text { Palmitinho } \\
\text { Pinheirinho do Vale } \\
\text { Planalto } \\
\text { Rio dos Índios } \\
\text { Rodeio Bonito } \\
\text { Rondinha } \\
\text { Seberi } \\
\text { Taquaruçu do Sul } \\
\text { Três Palmeiras } \\
\text { Trindade do Sul } \\
\text { Vicente Dutra } \\
\text { Vista Alegre }\end{array}$} & $\begin{array}{l}0,714 \\
0,754 \\
0,794 \\
0,796 \\
0,704 \\
0,731 \\
0,732 \\
0,740 \\
0,834 \\
0,714 \\
0,778 \\
0,720 \\
0,728\end{array}$ \\
\hline Erechim & ntre Rios c & 0,757 & & & \\
\hline Passo & $\begin{array}{l}\text { Pontão } \\
\text { Ronda Alta }\end{array}$ & $\begin{array}{l}0,761 \\
0,780\end{array}$ & & & 0,747 \\
\hline \multirow[t]{3}{*}{$\begin{array}{l}\text { Três } \\
\text { Passos }\end{array}$} & \multirow{3}{*}{$\begin{array}{l}\text { Barra do Guarita } \\
\text { Bom Progresso } \\
\text { Braga } \\
\text { Campo Novo } \\
\text { Crissiumal } \\
\text { Derrubadas } \\
\text { Esperança do Sul } \\
\text { Humaitá } \\
\text { Miraguaí } \\
\text { Redentora } \\
\text { Sede Nova } \\
\text { Tenente Portela } \\
\text { Tiradentes do Sul } \\
\text { Três Passos } \\
\text { Vista Gaúcha }\end{array}$} & \multirow{3}{*}{$\begin{array}{l}0,765 \\
0,754 \\
0,703 \\
0,736 \\
0,786 \\
0,759 \\
0,708 \\
0,802 \\
0,726 \\
0,669 \\
0,793 \\
0,769 \\
0,746 \\
0,822 \\
0,784\end{array}$} & & & $\begin{array}{l}0,706 \\
0,809 \\
0,813 \\
0,761 \\
0,769 \\
0,767 \\
0,744 \\
0,724 \\
0,764\end{array}$ \\
\hline & & & Ijui & $\begin{array}{l}\text { Condor } \\
\text { Coronel Bicaco } \\
\text { Panambi } \\
\text { Santo Augusto }\end{array}$ & $\begin{array}{l}0,793 \\
0,768 \\
0,820 \\
0,766\end{array}$ \\
\hline & & & \multicolumn{2}{|c|}{ Rio Grande do St } & 0,814 \\
\hline
\end{tabular}

Fonte: Atlas do Desenvolvimento Humano no Brasil (2003)

* O Município de São Pedro das Missões não consta do Atlas. Como esse município foi desmembrado, em abril de 1996, do Município de Palmeira das Missões, optou-se por completar a tabela estendendo para o primeiro o IDHM do segundo, admitindo a hipótese de que suas estruturas sejam muito semelhantes.

Quadro 1 - Índice de Desenvolvimento Humano Municipal (IDHM) na área de abrangência da COOPERBIO - 2000 
Biocombustíveis na busca de alternativas para a agricultura familiar: ações e expectativas da COOPERBIO no noroeste riograndense

Essa trajetória do setor agroindustrial se entrelaçou com a história do cooperativismo na área. Tal história registra um forte avanço do cooperativismo empresarial, fruto da transformação de estruturas cooperativas que, na primeira metade do século XX, foram criadas para que os produtores enfrentassem dificuldades de crédito e na produção. Essas cooperativas eram fortemente ligadas à ação pública e exibiam perfil comunitário, configurando organizações pequenas que aglutinavam grupos restritos de agricultores (Duarte, 1986). As grandes mudanças na economia brasileira a partir dos anos 50, destacando-se o desenvolvimento industrial, repercutiram no cooperativismo, pois aquelas estruturas mostraram-se incapazes de responder às exigências de um complexo agroindustrial calcado no cultivo de grãos e voltado ao mercado internacional. Assim, à modernização da agricultura articulou-se a modernização das cooperativas, o resultante cooperativismo empresarial acabando por agregar também pequenos agricultores em dificuldades: estes tiveram que procurar as cooperativas "quando surgiu a necessidade de trabalhar com o trigo e, posteriormente, com o soja, em função do crédito e subsídios abertos para estes produtos e do mercado promissor para os mesmos." (Op cit., p. 48).

Nessa incorporação, o pequeno produtor teve aprofundada a sua dependência frente às estruturas de perfil empresarial - até pela troca da sua produção costumeira pelo cultivo de grãos, exigente em insumos e equipamentos - e amargou uma piora na sua condição associativa. Motivo: o cooperativismo empresarial "relega o papel do cooperativado (principalmente os pequenos produtores) à sua função de usuário, eliminando o seu papel de dono (...)" (Op cit., p. 48-49). Essa vinculação mostrou-se particularmente adversa quando, decorrente das interações entre o modelo de cooperativismo empresarial e o capital financeiro (origem e nutriente de um forte endividamento causado pelas necessidades de financiamento no auge da soja), as cooperativas entraram em crise financeira no início dos anos 80 .

$\mathrm{O}$ endividamento despontou entre os fatores da crise que, castigando o cooperativismo do Rio Grande do Sul, aprofundou-se na década de 90 (Ew, 2001). A escassa capitalização do período anterior, a forte incidência de créditos de curto prazo, a elevação dos juros internacionais e a desvalorização da moeda brasileira (grande parte dos empréstimos era em dólares) perfilaram-se como vetores da crise. Posteriormente, a piora da conjuntura internacional no que respeita à soja, somando-se a fatores mais estruturais, 
referentes às próprias organizações cooperativas, agravou a situação, impondo a recomposição das condições de atuação do cooperativismo agropecuário. Vincula-se a esse processo a já mencionada relação entre o declínio da soja, após o boom dos anos 70, e a crise do sistema de cooperativas no Rio Grande do Sul, uma mistura com fortes repercussões no noroeste gaúcho. É esse o cenário da experiência ligada aos biocombustíveis tratada neste artigo: o noroeste gaúcho, apesar da histórica participação na escalada agroindustrial que projetou a Região Sul em nível de país, exibe numerosos bolsões de pobreza na zona rural e é área onde a crise do cooperativismo empresarial afetou profundamente os pequenos agricultores.

\section{COOPERBIO: OS PRIMEIROS PASSOS DE UMA EXPE- RIÊNCIA}

Esta seção baseia-se em pesquisa de campo na área da COOPERBIO, em 2007, na forma de entrevistas com dirigentes e quadros técnicos e de acompanhamento de reuniões.

\subsection{O sentido da COOPERBIO}

A concepção e a iniciativa de criação da COOPERBIO refletem o estágio dos debates, no âmbito do Movimento dos Pequenos Agricultores (MPA), sobre as possibilidades do cooperativismo organizado em bases comunitárias para a superação das dificuldades enfrentadas pela agricultura familiar. Segundo esses debates, as práticas produtivas agroecológicas são promissoras, pois ajudam a quebrar a dependência em relação aos insumos industriais. "A COOPERBIO surge desse processo. [A idéia é produzir] alimentos e também energia, com capacidade de garantir renda." (Técnico agrícola entrevistado)

Criada em 2005 na confluência das ações de vários movimentos sociais, mas sob a direção do MPA, a COOPERBIO objetiva, quanto aos biocombustíveis, organizar a produção e a venda de álcool hidratado e de óleo vegetal in natura (OVN). Em 2007 seu quadro dispunha de 15 técnicos agrícolas, 6 engenheiros agrônomos, 1 arquiteto, 1 químico industrial tecnológico, 1 engenheiro químico de alimentos e 1 engenheiro mecânico, distribuídos nas sedes regionais de Palmeira das Missões, Sarandi, Frederico Westphalen e Três Passos. 
Biocombustíveis na busca de alternativas para a agricultura familiar: ações e expectativas da COOPERBIO no noroeste riograndense

Durante a pesquisa, muitos cooperados estavam em fase de capitalização (adesão). Assim, embora se almejasse atingir 12 mil famílias, contava-se, então, só com algumas dezenas. As famílias formavam grupos de 8 a 10 produtores, com participação regida por contratos entre as famílias de cada grupo e entre os grupos e a cooperativa. $\mathrm{O}$ segundo tipo de contrato versa, além da disponibilidade de equipamentos, sobre a compra do combustível produzido, algo básico já que só a COOPERBIO (e não as famílias) pode vender à PETROBRAS. Merece realce que a COOPERBIO tivesse parcerias com a Empresa Brasileira de Pesquisa Agropecuária (EMBRAPA), a Associação Riograndense de Empreendimentos de Assistência Técnica e Extensão Rural (EMATER-RS), a Fundação Centro de Experimentação e Pesquisa (FUNDACEP), a Universidade Federal de Santa Maria (UFSM) e a Universidade Regional Integrada (URI), e convênios com a ELETROSUL e a PETROBRAS.

A pesquisa mostrou que a produção de biocombustíveis é considerada na cooperativa um instrumento para alcançar resultados verdadeiramente estratégicos do MPA: melhorar as condições de vida dos pequenos agricultores, usar a terra e os demais recursos de forma sustentável e organizar coletivamente as famílias, entre outros. Tal aspecto foi sublinhado em meio a indicações de que a produção de álcool e óleo combustível não constituíam um fim em si mesmo. A pretensão, ao menos das lideranças, é que o resultado econômico fosse parte de um projeto mais amplo, alternativo ao que se tornou dominante no cooperativismo da região.

\subsection{Iniciativas para produção de álcool}

No projeto da COOPERBIO, a produção de álcool tem na cana-deaçúcar a sua matéria-prima básica. Mas também se cogitava o uso de mandioca, cujo interesse se estende aos co-produtos (aproveitamento de raízes e folhas). A opção pela cana-de-açúcar transparecia no fato de que produtores desse vegetal já estivessem associados no período da pesquisa. Como o cultivo deveria ser consorciado, a idéia era disseminar prática de plantio com 1,5 metro de distância entre fileiras de cana intercaladas, por exemplo, com feijão-de-porco.

Uma única microdestilaria estava em funcionamento. Instalada no $\mathrm{Mu}-$ nicípio de Redentora (Microrregião de Três Passos) e operando havia alguns meses, tratava-se de um protótipo, com tecnologia alternativa, decorrente 
da parceria com a PETROBRAS. A condição era experimental, pois se buscava detectar a viabilidade técnica da produção, o que envolvia observar a qualidade do produto, isto é, o grau GL do álcool obtido (a ANP estabelece em 96 GL o patamar mínimo aceitável). Naquele momento já se havia constatado a viabilidade, pois os primeiros resultados foram satisfatórios: apesar do caráter temporário (a microdestilaria fora feita em numa cooperativa de metalúrgicos de Porto Alegre), obtivera-se álcool com 98 GL.

O projeto contemplava a criação de 9 microdestilarias, capazes de produzir 500 litros/dia cada uma e também aptas a gerar cachaça, melado e açúcar mascavo, e uma usina de retificação para processar 5.000 litros/ dia (localizada no Município de Frederico Westphalen). As microdestilarias deveriam ser operadas e geridas por grupos de famílias definidos segundo critérios de afinidade, de proximidade entre as propriedades e de quantidade de hectares disponíveis para o cultivo de cana-de-açúcar.

A Tabela 2, baseada em estimativas da própria cooperativa, oferece uma idéia sobre as necessidades de uma microdestilaria operada por grupo de 10 famílias. Os técnicos calculavam que, com produtividade média de 70 toneladas de cana-de-açúcar por hectare plantado, seria possível suprir a demanda por matéria-prima cultivando área de 2,5 hectares por família, a soma do grupo perfazendo 25 hectares. Durante a pesquisa, a COOPERBIO testava 50 mudas de variedades de cana, na expectativa de desenvolver variedade que permitisse uma média de 150 toneladas por hectare, mais que o dobro da produtividade vigente, o que representaria uma menor exigência de área por grupo de famílias.

Tabela 2 - Condições estimadas de operação de uma microdestilaria de álcool (grupos de 10 famílias)

\begin{tabular}{l|l}
\hline Itens & Quantificação \\
\hline Produtividade do cultivo da cana-de-açúcar & 70 toneladas/hectare \\
\hline Área total disponível para cultivo & 25 hectares \\
\hline Produção esperada de cana-de-açúcar & 1.750 toneladas \\
\hline Rendimento (álcool) por tonelada (de cana) & 70 litros de álcool/tonelada \\
\hline Rendimento (álcool) por hectare plantado & 4.900 litros de álcool/hectare \\
\hline Produção de álcool & 122.500 litros/ano \\
\hline Período de trabalho de 365 dias & 335,6 litros/dia \\
\hline Período de trabalho de 210 dias & 583,3 litros/dia \\
\hline Fonte: Elaboração própria com base em informaçoes obtidas na COOPERBIO
\end{tabular}


Biocombustíveis na busca de alternativas para a agricultura familiar: ações e expectativas da COOPERBIO no noroeste riograndense

Uma família de cada grupo deveria ceder parte do seu terreno para instalar a microdestilaria, baseando-se a escolha no tamanho da área disponível, nas condições de acesso e nos custos de transporte. A propriedade deveria dispor de área para armazenamento do vinhoto (resíduo aproveitável como insumo agroecológico, em adubação e alimentação do gado), fonte de água (necessária ao funcionamento da caldeira), eletricidade, capacidade de produção florestal (destinada à obtenção de lenha) e local para depositar a garapa. Os respectivos estudos eram de responsabilidade dos técnicos da COOPERBIO, a quem cabia mapear a propriedade, levantar os custos e montar a infra-estrutura. A COOPERBIO estimava em cerca de R $\$ 100$ mil o custo de implantação de uma microdestilaria, um valor referente só à instalação, sem o terreno e os custos agrícolas. As previstas 9 microdestilarias e a usina de retificação seriam instaladas com recursos da PETROBRAS, sem ônus para as famílias.

Para a operacionalização, considerava-se bastar um único trabalhador para o funcionamento da microdestilaria, ficando para cada grupo de famílias as tarefas de produção e moagem da cana-de-açúcar. Para a última tarefa, previa-se a compra de moendas móveis - por cerca de $\mathrm{R} \$ 30 \mathrm{mil}$ cada uma -, de modo a não ser preciso "levar a cana [para moer em outro lugar, distante da lavoura]; já fica o bagaço como adubo e a ponta da cana como alimento, para o gado ir comendo; e já vai estercando e urinando na lavoura" (Presidente da COOPERBIO em reunião para formar grupo familiar para produzir álcool).

Quanto ao uso do álcool, pretendia-se que uma parte fosse consumida pelas próprias famílias, e o excedente, vendido à PETROBRAS. Em caso de não cumprimento das determinações técnicas da ANP, o álcool das microdestilarias iria para a usina retificadora, para correção do grau GL, após o que seria comercializado. O envolvimento da PETROBRAS é, assim, essencial, possibilitando o escoamento do álcool: as atividades da cooperativa não podem incluir "a venda para o posto de gasolina; tem que vender para a distribuidora; temos um contrato pelo qual a PETROBRAS vai comprar toda a nossa produção" (Presidente da COOPERBIO em reunião para formar grupo familiar para produzir álcool).

O encadeamento exibe, portanto, produção de cana-de-açúcar e de álcool nos grupos familiares - organizados com base em contratos de parceria -; compra do combustível pela COOPERBIO, que, por contrato com cada grupo, 
fornece-lhes equipamentos; venda do álcool pela cooperativa à PETROBRAS. Essa estrutura tem implicações. "O papel da cooperativa é garantir a comercialização e a assistência técnica (...). Então, vamos ter que tirar daí a taxa de assistência técnica e a taxa de comercialização. Da sobra de vocês a gente tem que tirar uma parte para ajudar na capacitação, na formação" (Presidente da COOPERBIO em reunião). Ou seja, o vínculo dos agricultores é com a COOPERBIO, sem envolver a PETROBRAS. Se há alguma desistência, a cooperativa retira os equipamentos, pois o regime é de comodato.

\subsection{Iniciativas para produção de óleo vegetal}

Conforme assinalado, estruturas como a COOPERBIO têm participação apenas parcial na cadeia do biodiesel. Com a tecnologia disponível, podem produzir só o insumo principal, isto é, os óleos vegetais in natura (OVN). Assim, na COOPERBIO a transesterificação ficaria para a PETROBRAS.

\footnotetext{
Diferente do álcool, a última parte da cadeia do biodiesel é muito pesada [em investimento]. Só a parte final iria concentrar R $\$ 40$ milhões, enquanto todo o resto da cadeia produtiva concentra RS 60 milhões. Então precisaríamos de uma parceria estratégica, que tivesse gestão, poder e mercado, e que nos garantisse o escoamento." (Engenheiro agrônomo entrevistado)
}

Apesar do envolvimento só parcial, as perspectivas de produção eram consideradas boas, pois não é difícil obter o óleo. O processo de transformação não é muito complexo, como ocorre no álcool, e o custo de oportunidade é baixo, já que a produção da matéria-prima também pode ser consorciada. Esta, como observado, envolve culturas temporárias ou perenes, prevendo-se no projeto da COOPERBIO a utilização de 160 mil hectares para cultivos de ambos os tipos, em sistema de consórcio. Esperava-se que essa área fornecesse 120 milhões de litros/ano, com produtividade de 750 litros de óleo/ha/ano em média.

A maior aposta da cooperativa era a produção a partir de culturas perenes, não obstante a necessidade de "trabalhar no início com $80 \%$ de soja, porque é o que mais temos hoje; mas a previsão é ir diminuindo esse percentual e aumentar a participação das culturas perenes" (Técnico 
Biocombustíveis na busca de alternativas para a agricultura familiar: ações e expectativas da COOPERBIO no noroeste riograndense

agrícola entrevistado). A ênfase nessas culturas decorria do fato de que o tungue (arbórea que no sul do Brasil produz óleo para fabricação de tinta, com uso previsto pela COOPERBIO para produzir biocombustível) e o pinhão-manso (já usado para biocombustíveis em diferentes experiências no Brasil), as duas principais fontes contempladas, não têm custos de manutenção e plantio. Sua capacidade de produzir óleo vegetal e gerar renda desdobra-se no tempo, e em ambas é elevada a produtividade por hectare/ ano: até 1.500 litros de óleo no caso do tungue e pelo menos 2.000 litros no do pinhão-manso.

Assim, imaginava-se que com apenas 16 mil hectares seria possível obter 48,8 milhões de litros de óleo. Quer dizer, com 10\% da área planejada, se atenderia $40 \%$ da necessidade anual, ficando a área restante para produção de oleaginosas em consórcio com alimentos - por exemplo, "o cultivo da mamona em consórcio com feijão, amendoim, batata-doce e abóbora garante o uso eficiente dos recursos naturais" (Leal, s/d, p. 12) - sem caracterizar concorrência entre os dois tipos de cultivo. Para a mamona, assinale-se, as condições do Rio Grande do Sul são muito favoráveis devido à incidência de sol. Com manejo agroecológico e plantio consorciado, poder-se-ia obter anualmente cerca de mil litros de óleo por hectare plantado, segundo os técnicos da cooperativa.

Cabe assinalar que a COOPERBIO mantinha viveiro de mudas e tinha disponíveis cerca de 40 mil mudas de tungue, além de outras oleaginosas. Segundo o responsável pelo viveiro, pretendia-se que os cooperados comprassem as mudas através do PRONAF Florestal - com pagamento em dez anos, seis de carência e quatro para quitação - e, futuramente, incorporassem esse cultivo. Pensava-se igualmente fazer reflorestamento, plantando $8 \mathrm{mil}$ hectares com tungue e outro tanto com pinhão-manso, na expectativa de, em quatro anos, suprir $50 \%$ das necessidades com o óleo extraído dessas duas fontes.

Com base na definição das áreas de plantio, a cooperativa projetava a seguinte estrutura para extração de óleo vegetal: "uma unidade de 600 toneladas/dia, quatro de 60 toneladas/dia e dez de 500 a $1.000 \mathrm{~kg}$ por hora. Trazemos o óleo para a unidade principal e fazemos a retificação" (Engenheiro agrônomo entrevistado), com mistura dos óleos de diferentes origens. O funcionamento dessa estrutura implicaria a: 
- instalação de pequenas unidades esmagadoras comunitárias segundo um planejamento de consumo de tortas (feitas com resíduos do esmagamento de tungue, pinhão manso, mamona) na alimentação animal e na fertilização do solo ;

- instalação de unidades de médio porte (60 toneladas de grãos/ dia) em sistema de co-geração de energia elétrica (o que eleva os resultados econômicos, diminui custos de produção e aumenta os índices positivos do balanço energético);

- instalação de unidade de grande porte no Município de Palmeira das Missões, segundo se levantou, tecnicamente capaz de possibilitar tratamento e padronização para obtenção de óleo para alimentação humana e produção de biodiesel, e que canalizaria o óleo bruto transportado em caminhões desde as pequenas e médias unidades de esmagamento; o sistema de recebimento de óleo serviria para distintas matérias-primas e, mesmo com necessidade de mecanismos mais complexos para gerir os fluxos produtivos, as eventuais dificuldades seriam equacionadas pelo uso de "silos pulmões de menor porte" (Leal, s/d, p.15).

\subsection{A centralidade da unidade familiar e do sentido de coletividade}

No modelo contemplado, o processo produtivo deveria acontecer principalmente no nível da unidade familiar, em meio à forte interação entre os integrantes de cada grupo de famílias. Nesse esquema, os custos de produção apresentar-se-iam comparativamente menores, pois os resíduos significam insumos, a extração local do óleo e do álcool facilitando a utilização dos co-produtos, como indica a figura 1. É importante ressaltar que, na visão das lideranças entrevistadas, o sucesso do projeto vincula-se à natureza das relações entre as famílias, algo reconhecido entre os agricultores implicados: "Vai depender muito da confiança um no outro. Daí a importância de a gente não ter um grupo tão grande, e sim uma maior organização dos componentes, para se conseguir pensar como grupo" (Depoimento de agricultor em reunião). 
Biocombustíveis na busca de alternativas para a agricultura familiar: ações e expectativas da COOPERBIO no noroeste riograndense

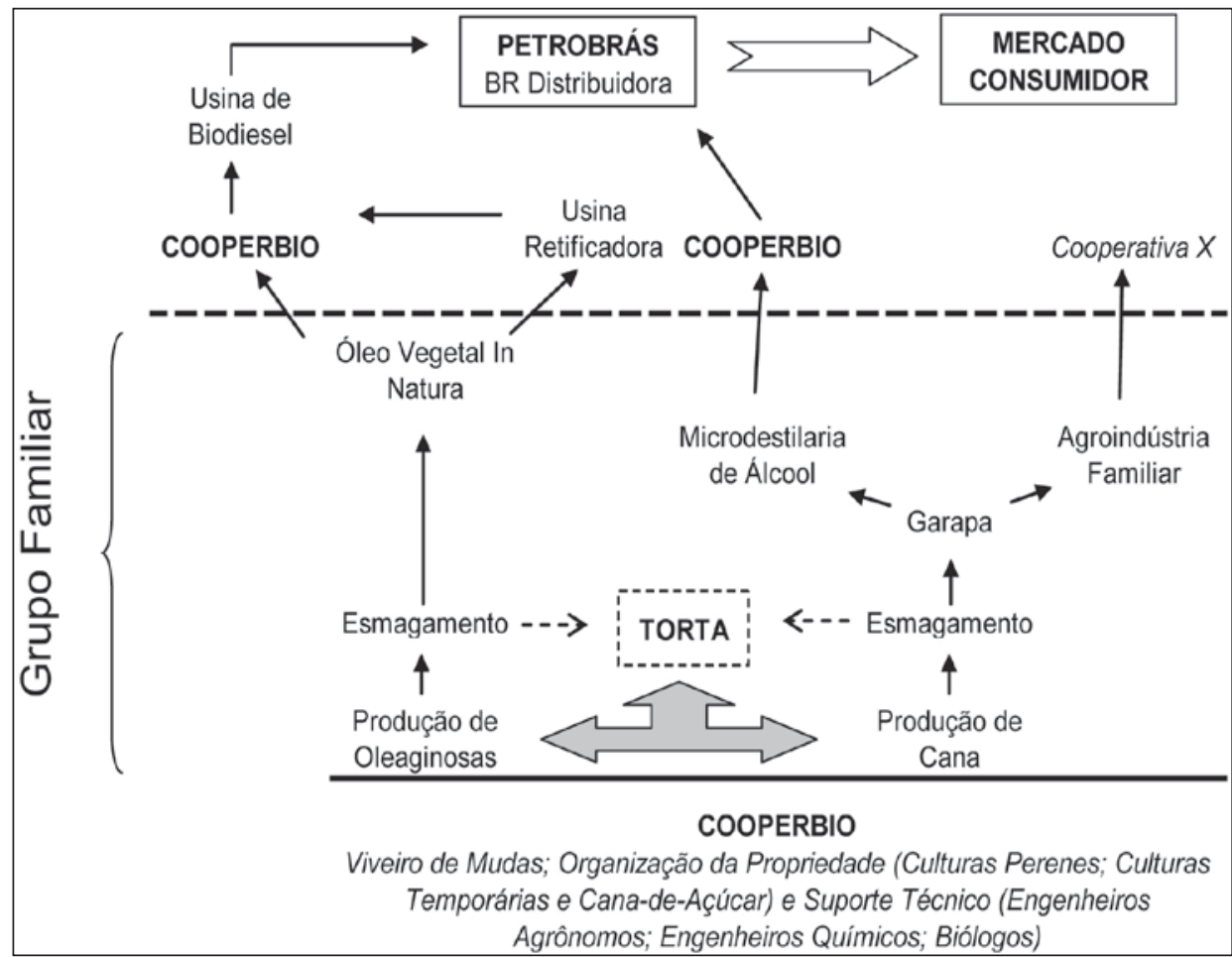

Fonte: Elaboração própria com base em informações obtidas na COOPERBIO

Figura 1 - Papel do grupo familiar na produção de álcool e biodiesel

Reconheceu-se que a organização interfamiliar é estratégica até para o usufruto dos benefícios do Selo Combustível Social, criado para incentivar a participação da agricultura familiar na cadeia produtiva do biodiesel por trazer vantagens aos produtores de combustível que compram matéria-prima de pequenos agricultores.

O ponto de vista positivo [do selo], qual é? Garante uma janela de participação, uma oportunidade, nos locais em que os pequenos agricultores estejam organizados. Obriga as empresas a [recorrer à] agricultura familiar por causa dos impostos. Então, a competitividade do biodiesel (...) [frente ao] diesel é garantida pelo selo social. Mas onde não tem agricultores organizados, estes só serão utilizados para fornecer matéria-prima. Então, aquilo que era uma oportunidade para os agricultores, passa a ser apenas uma vantagem para as empresas (...).” (Engenheiro agrônomo entrevistado) 
Mas o aceno de benefícios aos agricultores não significa dispensa de esforço de convencimento por parte da COOPERBIO sobre as vantagens da produção consorciada e da organização cooperativa. Sobre a segunda, a razão é clara: "nós temos medo de cooperativa aqui (...); tu falas de cooperativa, dá até dor de barriga", nas palavras de um agricultor, uma manifestação evocativa da assinalada crise do cooperativismo, fonte de consideráveis perdas para numerosos associados.

\section{COOPERBIO, AGRICULTURA FAMILIAR E DESENVOLVI- MENTO LOCAL: UMA DISCUSSÃO}

Protagonizada em região de pequenas propriedades rurais e precários indicadores de desenvolvimento, a experiência da COOPERBIO remete aos debates sobre agricultura familiar e desenvolvimento local. Não se cogita qualquer sumarização, mas algumas referências são úteis para balizar uma discussão sobre as possibilidades dessa cooperativa.

Exibindo envolvimento dos familiares na administração e condução da unidade produtiva e no fornecimento do essencial do trabalho utilizado, assim como a propriedade dos meios produtivos nas mãos da família (Guanziroli; Cardim, 2000), a agricultura familiar tradicionalmente enfrenta dificuldades, de uma maneira geral. Os problemas geralmente incluem obstáculos à negociação direta da produção, criando dependência de outros agentes - que auferem os maiores ganhos na comercialização -, e as implicações dos vínculos com a agroindústria, gerando obrigações (uso de insumos químicos, organização produtiva com intensa mecanização) e sujeição em vários níveis. A integração à lógica agroindustrial impõe maiores patamares de desempenho, piorando as condições das unidades que não logram participar, do que decorrem processos de exclusão (Abramovay, 1992).

Essa problemática da agricultura familiar entrelaça-se com a do desenvolvimento local. Amplamente falando, por "desenvolvimento local" se evoca campo de reflexão e formulação de políticas com vulto crescente em diferentes países. Não raramente essa expressão aparece acompanhada do adjetivo "endógeno", como em Vázquez Barquero (2001), o que. Garofoli (1992) sugere justificar-se "quando a maior parte dos recursos utilizados é de origem local (...). Nesse estágio, o sistema local pode estar apto a dirigir o seu próprio 
Biocombustíveis na busca de alternativas para a agricultura familiar: ações e expectativas da COOPERBIO no noroeste riograndense

processo de desenvolvimento e de transformação (...).” (p. 70). Não é ocioso assinalar que tal idéia é controversa. Dado o grau de interdependência atingido pelos processos econômicos, até internacionalmente, cabe ceticismo sobre a existência de processos “endógenos". Seja como for, essa questão perpassa estudos também sobre o meio rural, figurando entre os enfoques identificados por Kageyama (2004) sobre o correspondente desenvolvimento.

A imbricação entre as problemáticas da agricultura familiar e do desenvolvimento local, no que este põe em relevo as possibilidades dos "atores locais (...), através de suas respostas estratégicas, (...) [contribuírem] para os processos de transformação (...)" (Vázquez Barquero, op cit., p. 10), ajuda a pensar sobre o alcance da COOPERBIO. Tem realce nessa experiência a busca de alternativas para agricultores familiares castigados por adversidades, inclusive pela crise de um sistema cooperativista atrelado aos interesses dos grandes negócios de base agrícola. Daí que explorar caminhos para uma reprodução sustentada e menos sujeita àqueles interesses, com capacidade local para guiar processos de mudança - até com redefinição do sentido de comunidade rural e em sintonia com preocupações ambientais, como propugna Schneider (2004) -, configura, assim, procedimento estratégico. O que dizer do projeto COOPERBIO por esse ângulo?

Ficou claro na pesquisa que a iniciativa pretende criar opção na forma de contra-força à integração das famílias de agricultores à lógica da agricultura de perfil empresarial. Na argumentação, não raramente as lideranças da cooperativa recorreram à idéia de "autonomia", nas expectativas manifestadas, resultante de uma produção em sistema de consórcio: nos termos de uma bióloga da COOPERBIO, "tudo o que a gente falou aqui sobre álcool e biodiesel foi pensando em autonomia, pensando no cara não ficar dependente de nada". Tem coerência com isso o estímulo ao plantio espaçado da cana-de-açúcar, intercalando com, por exemplo, feijão, amendoim e batata. O mesmo vale para a idéia de reservar para o gado as áreas internas das superfícies plantadas com oleaginosas. Isso representa estímulo à produção leiteira (contemplava-se o Pastoreio Racional Voisin , um sistema coerente com os princípios da agroecologia) na expectativa da anunciada vinda de empresas do ramo para a região, ou da ampliação das suas atividades (Nestlé, Embaré, Coorlac). Daí a ênfase no planejamento da totalidade das atividades em cada propriedade, sob a lógica da alterna- 
tividade, do cultivo de uso múltiplo: "da cana, por exemplo, se faz álcool, cachaça, suco, açúcar mascavo, comida para o gado, adubo" (Engenheiro agrônomo entrevistado)

A agroecologia, pretendida base do processo produtivo, vincula-se a tais aspectos. $\mathrm{Na}$ ótica defendida, o uso das correspondentes técnicas garantiria ao agricultor a reprodução do seu sistema sem necessidade de compra de insumos. Na outra ponta, mas também ligada ao interesse em "quebrar" a dependência do sistema industrial, a cooperativa visava atuar no escoamento dos produtos, uma das principais preocupações dos pequenos agricultores, historicamente. Desse modo, se o escoamento dos biocombustíveis envolve a PETROBRAS, a comercialização dos alimentos implica outra cooperativa ligada ao MPA, que compra dos produtores e à Companhia Nacional de Abastecimento. O previsto crescimento da produção leiteira consorciada à de biocombustíveis deveria usufruir dessa estrutura.

Assim, as manifestações denotavam expectativa de impactos locais consideráveis. De fato, além dos ganhos monetários na produção de energia, o agricultor haveria de se beneficiar com o autoconsumo, do que resultaria produção mais barata de alimentos, diretamente (pelo uso do combustível) e indiretamente (pelo uso de co-produtos como torta, bagaço e vinhoto na correção do solo e na alimentação de animais). Havia igualmente a pretensão de que o projeto fosse "ambientalmente correto", pela renúncia ao uso de agrotóxicos,o que significaria benefícios tanto no meio-ambiente imediato quanto para a saúde do produtor rural.

O feixe de iniciativas é, portanto, sedutor, pelos acenos mais que implícitos. Todavia, cabe indagar sobre as possibilidades da COOPERBIO considerando as problemáticas da agricultura familiar e do desenvolvimento local no noroeste do Rio Grande do Sul. O aspecto mais emblemático do empreendimento diz respeito à busca de autonomia dos pequenos agricultores perante o sistema agroindustrial, razão de ser da ênfase tanto na produção consorciada quanto no aproveitamento dos co-produtos do álcool e do óleo combustível. Esse aspecto combina-se ao da possibilidade de comandar localmente o processo de mudança e desenvolvimento, um assunto caro ao debate sobre desenvolvimento local.

É importante assinalar que o protagonismo local em relação aos biocombustíveis estará irrevogavelmente vinculado a uma grande estrutura 
Biocombustíveis na busca de alternativas para a agricultura familiar: ações e expectativas da COOPERBIO no noroeste riograndense

externa: a PETROBRAS. Isso quer dizer que as condições de atuação da COOPERBIO serão em grande parte ditadas pelo funcionamento dessa empresa, sem qualquer possibilidade de interferência dos agricultores, cujo poder de barganha em face da lógica que rege o comportamento daquele organismo é simplesmente nulo. Por sua vez, a PETROBRAS opera em meio a condicionantes para o setor de energia cuja determinação situa-se em escala planetária. Assim, integrar a estrutura da PETROBRAS, mesmo nos termos definidos, significa sujeição a esses condicionantes, devido à "correia de transmissão" entre as esferas global e local que tal envolvimento representa. Por conseguinte, a hipótese do desenvolvimento "endógeno", com autonomia, mostra-se excessivamente otimista.

De outra parte, no que toca à matéria-prima para o óleo combustível, seria necessário usar inicialmente cerca de $80 \%$ de soja. Como, segundo admitido nas entrevistas, os pequenos agricultores têm dificuldades para cultivar soja (problemas de escala e exigências envolvendo maquinário), a produção de óleo iria depender das colheitas das grandes propriedades da região, um vínculo que provavelmente se estenderá no tempo. Cabe mesmo dúvida se, haja vista a tradição sojicultora da área, essa oleaginosa perderá espaço para as culturas perenes como matéria-prima, a despeito da arquitetura do projeto.

Ocorre que soja proveniente da agricultura empresarial significa matéria-prima conectada ao grande capital, inclusive multinacional, que atua vigorosamente nas áreas de sementes e fertilizantes, entre outras. Ressalte-se também ser evidente o papel da soja na modelagem da paisagem do biodiesel no Brasil, fiel à volúpia com que tal segmento agrícola avança nesse mercado (Medina, 2006): das 38 autorizações para produzir biodiesel concedidas pela Agência Nacional do Petróleo, Gás Natural e Biocombustíveis (ANP, 2007) até o início do segundo semestre de 2007, 25 referiam-se às regiões sudeste e centro-oeste, figurando o Estado do Mato Grosso com o maior número (10), seguido de São Paulo (9). A Região Noroeste, epicentro histórico da "questão regional" brasileira, registrava meros 13\%. Tal fato, somado ao envolvimento apenas marginal dessa região no atual frenesi do álcool (Lobato, 2007), permite interrogar sobre o real alcance da presente investida nos biocombustíveis em termos de promoção do desenvolvimento local-regional e de enfrentamento das disparidades socioespaciais, como 
acentuado no discurso oficial. Para o que interessa neste artigo, questão chave é que o vínculo com a soja certamente significa comprometimento de uma das pedras angulares do ideário da COOPERBIO: a autonomia das famílias de agricultores.

De todo modo, o projeto dessa cooperativa tem repercutido na mesorregião. É natural que assim seja, pois previam-se investimentos iniciais da ordem de $\mathrm{R} \$ 2,3$ milhões nas microdestilarias e de aproximadamente $\mathrm{R} \$ 100$ milhões na produção de biodiesel, com benefícios para cerca de 30 mil famílias de pequenos agricultores. Não surpreende, desse modo, que o projeto contasse com apoio das administrações municipais, embora a questão fiscal figurasse como a principal causa desse suporte: quando interrogado sobre a contribuição das prefeituras à execução do projeto, um dos interlocutores, pertencente ao quadro técnico da cooperativa, ponderou que estas

estão [contribuindo, mas] muito em função da PETROBRAS e do seu [próprio] desespero, porque a renda desses municípios é o Fundo de Participação dos Municípios; as outras rendas são muito pequenas, e caíram muito nos últimos anos. Em Palmeira [das Missões] caíram mais de 45\%. Os prefeitos estão desesperados, estão todos indo para o Tribunal de Contas (Técnico agrícola entrevistado).

Nesse quadro, compreende-se que as prefeituras priorizem a diversificação das suas fontes de receita. Isso envolve impulsionar a economia local, gerando aumento de arrecadação através de novos empreendimentos. Intervenção de representante da Prefeitura de Erval Seco, em reunião da COOPERBIO com grupo de agricultores, exprimiu essa preocupação: "[o álcool] é um produto industrializado; como é que Erval Seco fica nessa história? A comunidade está aceitando muito bem esses programas de agroindústria, que são não apenas para melhorar a renda da família, mas também para aumentar a própria arrecadação do municio".

Esse assunto remete ao problema da arrecadação tributária gerada pelo projeto para cada município. Por exemplo, no que concerne ao biodiesel, a comercialização será realizada a partir da usina central, localizada em Frederico Westphalen. Sendo assim, a cooperativa deverá mediar acordo entre os municípios para que todos recebam um montante proporcional à sua participação no processo produtivo. Segundo o presidente da coope- 
Biocombustíveis na busca de alternativas para a agricultura familiar: ações e expectativas da COOPERBIO no noroeste riograndense

rativa, "vai haver um acordo tributário entre os secretários da fazenda dos municípios conveniados com a COOPERBIO; [cada um] vai receber o rateio proporcional ao montante da produção" (Presidente da COOPERBIO em reunião para formar grupo familiar produtor de álcool).

\section{CONSIDERAÇÕES FINAIS}

A COOPERBIO representa tentativa de exploração, por movimentos sociais presentes no noroeste gaúcho, das possibilidades de melhoria nas condições de vida dos pequenos agricultores decorrentes da maré montante dos biocombustíveis no Brasil. Um histórico de adversidades na região, com destaque para os reflexos da crise do cooperativismo de perfil empresarial, favoreceu e estimulou a opção por essa alternativa. Trata-se, contudo, de experiência singular, não podendo ser tomada como representativa do que ocorre na agricultura familiar em escala local, e muito menos em todo o Rio Grande do Sul. As iniciativas observadas enfeixam-se nas ações dos movimentos sociais e dizem tão-somente respeito ao arco de abrangência destas. Como reconheceu o presidente da COOPERBIO, "a cooperativa nasceu do movimento e é uma das poucas que está nas mãos do MPA". Assim, deve-se considerar muito mais como ma expressão entusiasmada de desejo uma manifestação como esta, lançada numa reunião: "esse processo de produção de energia e de alimentos [de forma conjugada] é muito maior; não é só para transformar a comunidade, mas é para mudar o Brasil". Ou esta outra, do presidente da cooperativa, em tom de exortação: "vocês não têm idéia do desafio que estão assumindo; vocês são os protagonistas, e os primeiros sempre têm que abrir todos os caminhos com maior dificuldade; mas temos que mostrar que dá certo."

Não há nada errado no entusiasmo e na postura de incitação. Mas é importante ter plena consciência sobre as dificuldades. Os dirigentes da COOPERBIO frisam que se trata de "um novo modelo cooperativista; a idéia é que o controle esteja na mão de vocês", como exposto pelo presidente em reunião. Mas os vínculos que necessariamente enredarão as atividades de produção de álcool e óleo combustível permitem escassas (se algumas) ilusões sobre isso. Além do mais, é justo postular que a continuidade do empreendimento depende amplamente do resultado econômico dos primeiros anos, sobretudo porque os participantes são agricultores familiares calejados 
pelas frustrações do cooperativismo. Nesse caso, por mais que os sentidos de coletividade e solidariedade se mostrem enraizados, o arrebatamento que se julgou detectar em alguns agentes poderá desvanecer, e os agricultores possivelmente se voltarão para outras atividades.

Seja como for, a experiência da COOPERBIO, embora específica, é ilustração de como contingentes organizados percebem as suas possibilidades no atual contexto brasileiro e agem de acordo. Apesar das interrogações, é, no mínimo, iniciativa a ser acompanhada, avaliada e discutida.

\title{
BIOFUELS IN THE SEARCH OF ALTERNATIVES TO FAMILY FARMING: INITIATIVES AND EXPECTATIONS OF COOPER- BIO IN THE NORTHWEST OF RIO GRANDE DO SUL
}

\begin{abstract}
Biofuels production might represent a new opportunity to Brazilian small family farmers. This article explores this issue in a study about the Cooperativa Mista de Produção, Industrialização e Comercialização de Biocombustíveis do Brasil Ltda. (COOPERBIO), created in 2005 by rural social movements in the Northwestern region of Rio Grande do Sul. After indicating the general features of biofuels production and describing the region, the article presents the actions towards ethanol and oil production, by groups of families, coupled with food production according to principles of agroecology. The possibilities represented by such initiative to small family farmers and to local development are discussed.
\end{abstract}

Keywords: Biofuels, COOPERBIO, small family farming

\section{REFERÊNCIAS BIBLIOGRÁFICAS}

A BRIGHTER future? The Economist, Feb. 10 $0^{\text {th }}$ 2001. A Survey of Energy.

ABRAMOVAY, R. Paradigmas do capitalismo agrário em questão. São Paulo: Hucitec: Anpocs: Ed. da Unicamp, 1992. 
Biocombustíveis na busca de alternativas para a agricultura familiar: ações e expectativas da COOPERBIO no noroeste riograndense

ALVES, T. W. Fatores do crescimento regional agropecuário no Rio Grande do Sul - 1970-96. Ensaios FEE, 27(1): 233-272, 2006.

AMPLIAÇÃO da produção de etanol e co-geração de energia elétrica. SEMINÁRIO BNDES: ÁLCOOL - POTENCIAL GERADOR DE DIVISAS E EMPREGOS. 25-26 ago. 2003. Disponível em: <www.bndes.gov.br/ conhecimento/seminario/alcool_discussao.pdf> Acesso em: ago. 2007.

ANDREOLI, C.; SOUZA, S. P. de. Cana-de-açúcar: a melhor alternativa para conversão de energia solar e fóssil em etanol. Economia \& Energia, n ${ }^{0}$ 59, dez. 2006. Disponível em: $<$ http://ecen.com/eee59/eee59p/cana_melhor_conversor.htm> Acesso em: ago. 2007.

ANP. Agência Nacional do Petróleo, Gás Natural e Biocombustíveis. Petróleo e Derivados. Disponível em: <www.anp.gov.br/doc/petroleo/ AutorizacoesBiodiesel.doc> Acesso em: set. 2007.

ATLAS do Desenvolvimento Humano no Brasil. Brasília: PNUD/IPEA/ FJP, 2003.

BANDEIRA, P. A economia da Região Sul. In: AFFONSO, R. de B. A.; SILVA, P. L. B. (Orgs.). Desigualdades regionais e desenvolvimento. São Paulo: FUNDAP: Ed. da Universidade Estadual Paulista, 1995, p. 225-251.

BANDEIRA, P. Origens, evolução e situação atual das desigualdades regionais no Rio Grande do Sul. In: GONÇALVES, M. F.; BRANDÃO, C. A.; GALVÃO, A. C. (Orgs.). Regiões e cidades, cidades nas regiões: o desafio urbano-regional. São Paulo: Editora UNESP: ANPUR, 2003, p. 519-548.

BRASIL. Ministério de Minas e Energia. Balanço Energético Nacional 2007: Ano base 2006: Resultados Preliminares. Rio de Janeiro: EPE, 2007.

CARACTERIZAÇÃO e tendências da rede urbana do Brasil: redes urbanas regionais: Sul / IPEA, IBGE, UNICAMP / IE / NESUR, IPARDES. Brasília: IPEA, 2000. 
CASTILHOS, C. C. Políticas públicas e desenvolvimento de arranjos produtivos locais: reflexões sobre o programa gaúcho. In: FAURÉ, Y.-A.; HASENCLEVER, L. (Orgs.). Caleidoscópio do desenvolvimento local no Brasil: diversidade das abordagens e das experiências. Rio de Janeiro: E-papers, 2007, p. 241-267.

DUARTE, L. M. G. Capitalismo \& cooperativismo no R. G. S. Porto Alegre: L\&PM: ANPOCS, 1986.

EW, A. R. Reestruturação do cooperativismo agropecuário no Rio Grande do Sul: os casos COSUEL e COAPEL - anos 90. Porto Alegre, 2001. Dissertação (Mestrado em Economia Rural) - Universidade Federal do Rio Grande do Sul.

FRÖHLICH, E. R. et al. Níveis de confiança e desenvolvimento agrícola no Rio Grande do Sul. Perspectiva Econômica, 31(94): 85-109, 1996.

GAROFOLI, G. Les systèmes de petites entreprises: un cas paradigmatique de développement endogène. In: BENKO, G.; LIPIETZ, A. (Dirs.). Les régions qui gagnent. Paris: Presses Universitaires de France, 1992, p. 57-80.

GUANZIROLI, C. E.; CARDIM, S. E. de C. S. (Coords.). Novo retrato da agricultura familiar: o Brasil redescoberto. Brasília: Projeto de Cooperação Técnica INCRA/FAO, 2000. Obtido em: <www.rlc.fao.org/proyecto/ brazil/censo.pdf> Acesso em: set. 2007.

KAGEYAMA, A. Desenvolvimento rural: conceito e medida. Cadernos de Ciência \& Tecnologia, 21(3): 379-408, 2004.

LAZZARI, M. R. Soja gaúcha avança sobre áreas de milho e de pecuária. Carta de Conjuntura FEE, 14(3): 2, mar. 2005.

LEAL, M. Agricultura camponesa e biomassa: um outro projeto é possível. Palmeira das Missões: COOPERBIO, s/d. Disponível em: <www. cooperbio.com.br> Acesso em: ago. 2007. 
Biocombustíveis na busca de alternativas para a agricultura familiar: ações e expectativas da COOPERBIO no noroeste riograndense

LOBATO, E. Nordeste vê à distância explosão do álcool. Folha de S. Paulo, p. B1, 8 jul. 2007.

MEDIDA Provisória nº 214, de 13 de setembro de 2004.

MEDINA, H. Soja avança sobre o mercado do biodiesel. Folha de S. Paulo, p. B1, 19 nov. 2006.

MERTZ, M. A agricultura familiar no Rio Grande do Sul - um sistema agrário "colonial”. Ensaios FEE, 25(1): 277-298, 2004.

RESOLUÇÃO n ${ }^{\circ}$ 42, de 24 de novembro de 2004. Diário Oficial da União, $n^{\circ} 236$, de 9/12/2004.

SCHNEIDER, S. As transformações recentes da agricultura familiar no Rio Grande do Sul: o caso da agricultura em tempo partial. Ensaios FEE, 16(1):105-129, 1995.

SCHNEIDER, S. A abordagem territorial do desenvolvimento rural e suas articulações externas. Sociologias, 6(11): 88-125, 2004.

UnB - Universidade de Brasília. Produção de biocombustíveis a partir de óleos vegetais e gorduras. Brasília: UnB. Projeto. s/d. Disponível em: $<$ www.unb.br/lmc/biooleo.htm> Acesso em: ago. 2007.

VÁZQUEZ BARQUERO, A. Desenvolvimento endógeno em tempos de globalização. Porto Alegre: FEE: Editora da UFRGS, 2001.

Artigo recebido em março de 2009 e aceito para publicação em novembro de 2009. 